\title{
Experimental Study of Flow Field and Movement of Sediment over a Ramp
}

\author{
Binit Kumar ${ }^{1}$, Subhojit Kadia ${ }^{2}$, Zulfequar Ahmad ${ }^{1}$ \\ 1. Department of Civil Engineering, IIT Roorkee, Roorkee 247667, India, \\ Email: binit.nit2010@gmail.com,zulfifce@gmail.com \\ 2. Department of WRD \& M, IIT Roorkee, Roorkee 247667, India, \\ Email: subhojitkadia@gmail.com
}

Received: 19 October 2018; Accepted: 9 November 2018; Available online: 1 March 2019

\begin{abstract}
Applications of hydraulic structures in low dams and diversion structures in countries like India, where sediment is a serious concern, demands a good expanse of research on the flow field and movement of sediment. The present study was focused on the non-uniformity in the velocity distribution along the flow direction and the movement of sediment over a ramp. The velocity distribution of the flow near and over the ramp was studied with the help of Acoustic Doppler Velocimeter. Experiments were conducted to study the mechanics and kinematics of movement of sediment particles. The movement of sediment particles over the smooth ramp was studied with the help of high-speed camera system. The particle velocity, acceleration, applied force and the angle of velocity vector were processed and analyzed from the captured images using digital image analysis techniques. The path of the movement of sediment particle was tracked. The vector results of the flow pattern indicated a very high amount of increase of the uplift velocity ( $y$ - component of the instantaneous flow velocity) component over a ramp. The sediment had very little movement for about 3.8 seconds at the beginning of the ramp and accelerated as it moved along the ramp in the downstream side. The path of the sediment movement over the ramp was found to be inclined by 25.6 to 35.7 degree to the horizontal axis which was almost parallel to the ramp ( 29.055 degree). Keywords: Flow field; Sediment movement; Ramp; Sediment mechanics.
\end{abstract}

\section{Introduction}

The movement of sediment particles on a river bed and over the hydraulic structures depends on two parameters i.e. critical tractive shear stress and bed shear stress. The sediment particles start moving only when the bed shear stress due to flow velocity exceeds the critical shear stress [1-3]. Sediment transport is a serious concern in present era as it is affecting the course as well as the morphology of the river [4-5]. The movement of particles depends on different factors such as flow conditions, the densities of fluid and sediment and the size of the particle. The movement of sediment particles mainly depends on three characteristics namely fluid characteristics, flow characteristics and sediment characteristics [3-4]. The interactions between flow and the bed load transport was studied in detail by Meyer- Peter and Muller [6] and Parker [7]. The movement of particles have been traced with the high-speed cameras and video recording process [8-14].

Abbott and Francis [9] studied the trajectories of solitary grains in water stream by the help of thousands of photographs taken during the movement of particles. They observed the positions, velocities and the acceleration of the grains at different positions. The author had presented the three modes of transport i.e. rolling, saltation and suspension of the particles and its proportion at different stages of flow. The development of suspension is much less as compared to saltation from rolling.

Three conditions are required for the establishment of the incipient motion of sediment particles: competency, lift concept and the critical tractive force [3]. In order to find the critical shear velocity of movable rough bed, Shields [1] and Yalin and Karahan [2] methods are useful. Literatures suggest the use of Prandtl-Karman logarithmic equation [15-16] for smooth bed to calculate the shear velocity and bed shear stress [14,17].

Kothyari et al. [18] and Jain et al. [19] have indicated the need of deep hydraulic knowledge for the modeling of soil erosion process over the transitionally rough bed. Ramesh et al. [14] carried out the experimental studies using high-speed cameras and observed the movement of sediment particles for a transitionally rough bed. The different sizes of the sediment were used for the experimentation purpose. The movement of the particles was observed by the high-speed cameras and the trajectories were plotted using image processing software. The position, velocity and the acceleration of the sediment particles were obtained by using the digital image processing techniques. The acceleration variation and the angle fluctuation were of bell shaped. The data given in the literature can be used for the stochastic modeling of the bed load transport [14]. 
The present study deals with the flow field and the movement of sediment particle over a ramp. The flow pattern near and over the ramp was measured and the velocity vectors were calculated for the better understanding of flow near the ramp. The literature survey shows that there are very few studies on the movement of sediment particles over the hydraulic structures. The authors have traced the path of sediment particles and related it with the flow pattern. This will be very helpful in maintaining the continuity of sediment over the structures and protecting the structures from the scouring.

\section{Experimental set-up}

The experimental work was performed in the long flume of Hydraulics laboratory of Civil Engineering Department, Indian Institute of Technology Roorkee, India. The size of the flume was $15 \mathrm{~m}$ long, $0.39 \mathrm{~m}$ wide and $0.52 \mathrm{~m}$ high with fixed bed. A ramp was fabricated by the acrylic sheet of thickness $6 \mathrm{~mm}$ and installed in the flume. The water was supplied by the inlet pipe fixed at the entrance of the flume. A honeycomb structure of masonry grid wall was provided at the inlet tank to minimize the disturbances created by the flow. A wooden floater was provided at the upstream of the ramp to make the flow stable and uniform. A tailgate of iron sheet is provided at the downstream to adjust the depth of tail water. The wall of the flume is made up of glass for the visual observations of experimental work. The point gauge was used to measure the hydraulic head up to \pm 0.1 $\mathrm{mm}$ accuracy and the discharges were measured by the help of ultrasonic flow meter. The instantaneous flow velocities (three-dimensional velocity components) were measured with the help of ADV (Acoustic Doppler Velocimeter) using a $10 \mathrm{MHz}$ of Nortek-AS as shown in Figure 1.

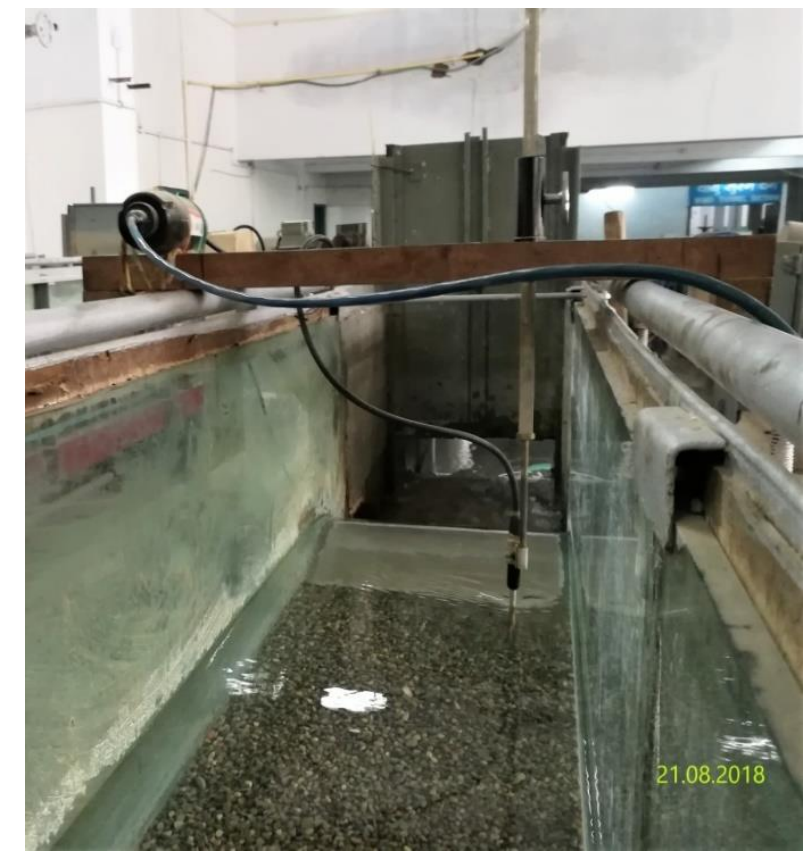

Figure 1. Setup with Acoustic Doppler Velocimeter

The movement of sediment particles was photographed using a high-speed camera of IMPERSX (IPXVGA210L), which is attached to the workstation computer having the frame grabber card. The images were taken at a resolution of $320 \times 480$ with 207 frames/s frame rate. The image was captured by the high-speed camera by using STREAMPIX software designed by a specialized code to provide the real time digital video. The captured videos were processed and analyzed by the software known as IMAGE-PRO PLUS.

\section{Experimental conditions}

The experiments related to the flow field study were performed under steady, turbulent, sub-critical conditions of the flow. Three tests with discharges $13.25,16.5$ and $21.5 \mathrm{l} / \mathrm{s}$ were considered for the study. The distributions of the flow velocities along the flow depth were measured by the ADV at 19 grid points as shown in Figure 2. For the ADV the sample rate was set as $50 \mathrm{~Hz}$ and the data were measured for 60 seconds. The vertical intervals along the flow depth were kept less i.e. $0.2-0.5 \mathrm{~cm}$ near the bed and the same were gradually increased towards the free surface. The recorded raw data were filtered based on minimum SNR of 15 and minimum COR of 70 [20-21]. 
These values were further analyzed and the mean velocity values on the XY plane were calculated and used for the development of the vector diagrams. The filtered velocity data at several levels along the flow depth and the corresponding distances from the bed level were used in regression technique in the Prandtl-Karman logarithmic equation [15-16] for rough bed condition to calculate the shear velocity and eventually the bed shear [17]. For these 3 flow conditions the critical bed shear stress for rough bed material upstream of the ramp having sediment size $\mathrm{D}_{50}=5.5 \mathrm{~mm}$ was obtained using the well-known Yalin-Karahan approach [2-3]. The computed critical bed shear stress $\left(4.01 \mathrm{~N} / \mathrm{m}^{2}\right)$ was found to be very high than the shear stress obtained during experiments and no sediment movement over the rough upstream bed was observed. The hydraulic parameters and test conditions used in the study are listed in Table 1.

Table 1. Hydraulic parameters

\begin{tabular}{llll}
\hline Parameters & $\mathrm{Q}=13.25 \mathrm{l} / \mathrm{s}$ & $\mathrm{Q}=16.5 \mathrm{l} / \mathrm{s}$ & $\mathrm{Q}=21.5 \mathrm{l} / \mathrm{s}$ \\
\hline Flow depth $\mathrm{h}(\mathrm{cm})$ & 16.255 & 17.4225 & 18.735 \\
Shear velocity $u_{*}(\mathrm{~cm} / \mathrm{s})$ & 1.617 & 2.043 & 2.57 \\
Shear stress $\left(\mathrm{N} / \mathrm{m}^{2}\right)$ & 0.261 & 0.417 & 0.66 \\
Roughness size $\mathrm{k}_{\mathrm{s}}(\mathrm{cm})$ & 0.7879 & 0.9802 & 1.2654 \\
$\mathrm{k}_{\mathrm{s}}^{+}=\mathrm{u}_{*} \mathrm{k}_{\mathrm{s}} / \nu$ & 159.07 & 250.07 & 406.09 \\
Hydraulic radius $(\mathrm{cm})$ & 8.87 & 9.2 & 9.55 \\
Mean velocity $(\mathrm{cm} / \mathrm{s})$ & 20.9 & 24.283 & 29.425 \\
\hline
\end{tabular}

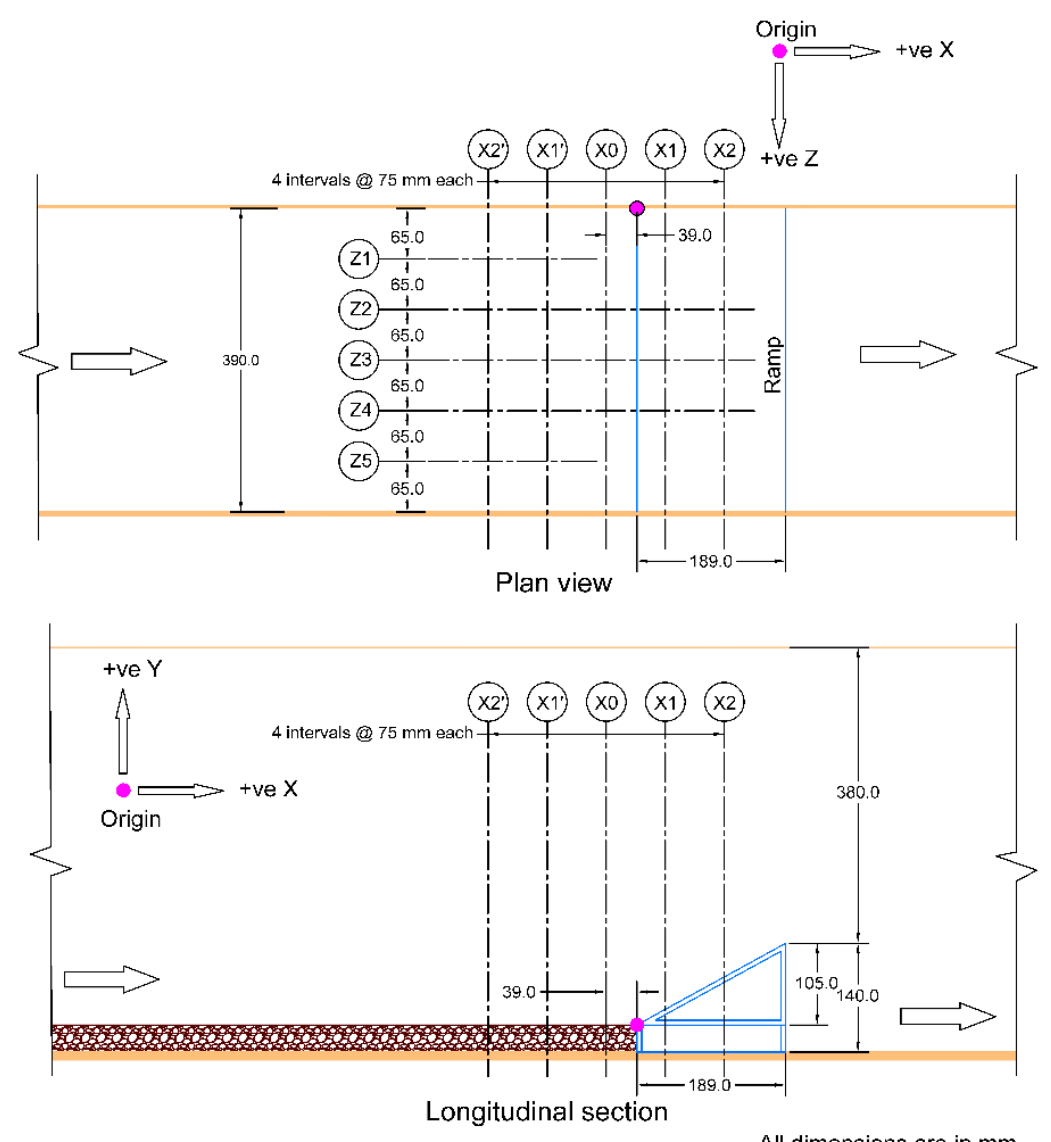

Figure 2. Index map near ramp (Plan and Longitudinal section)

On the other hand, the movement of a sediment particle of size $2.18 \mathrm{~mm}$ over a smooth upstream bed and ramp was experimentally studied. The experiment was started with a discharge $15.95 \mathrm{l} / \mathrm{s}$ and was gradually increased. The movement of $2.18 \mathrm{~mm}$ sediment particle over the smooth upstream bed and ramp was started at discharge values $17.1 \mathrm{l} / \mathrm{s}$ and $21.15 \mathrm{l} / \mathrm{s}$ respectively. The velocity distribution of the flow field in the upstream of ramp for those two discharge values were measured using ADV to quantify the additional bed shear stress required on the upstream smooth bed for the movement of sediment over the ramp. 


\section{Results and discussions}

\subsection{Flow characteristics}

The velocity values measured using the ADV at grid points along the flow depth and up to a depth of 6-7 cm from the free surface were filtered for SNR and COR. The filtered data used to draw the above vector diagrams. As listed in Table 2, it was observed that there was a high amount of rise in the upward velocity component within the ramp as compared to the rise in the approach flow which is helpful in the movement of sediment over the ramp. It also appears to be that there is a boundary layer created above the ramp due to flow separation within which the flow is having backward longitudinal velocity (shown in Figure 3). This appears to be similar to what has been explained by Garde and Mirajgaoker [22].

Table 2. Comparison of mean vertical upward velocity

\begin{tabular}{cccccc}
\hline \multirow{2}{*}{ Discharge $(1 / \mathrm{s})$} & \multicolumn{5}{c}{ Mean vertical velocity $(\mathrm{cm} / \mathrm{s})$ at different sections } \\
\hline 13.25 & $\mathrm{X} 2^{\prime}$ & $\mathrm{X} 1^{\prime}$ & $\mathrm{X} 0$ & $\mathrm{X} 1$ & $\mathrm{X} 2$ \\
16.5 & 0.106 & 0.374 & 1.619 & 6.028 & 11.886 \\
21.5 & 0.032 & 0.512 & 1.971 & 5.531 & 10.430 \\
\hline
\end{tabular}

\subsection{Particle tracking procedure}

Sediment of size $2.18 \mathrm{~mm}$ and relative density 2.64 was fed $1.8 \mathrm{~m}$ upstream of the ramp so that the feeding point did not distract the image capturing. The particle movement was captured by the camera having a high frame rate. The captured field was having length $280 \mathrm{~mm}$ and height $207.5 \mathrm{~mm}$. Resolution of the field was $320 \mathrm{x} 480$ pixels. The pixel sizes along the horizontal and vertical directions were $0.875 \mathrm{~mm}$ and $0.432 \mathrm{~mm}$ respectively. The instantaneous particle motion characteristics at different time steps were calculated using the forward difference technique and the consecutive positions of the particle for different time intervals as given in the literature [1314]. The relative positions of sediment along the path of movement is shown in the Figure 4(a-b), given below. During tracking, a high amount of variation in particle velocity along its path of movement was observed and therefore different time intervals at three different parts were adopted. The whole path of sediment movement was divided into 3 parts: approaching, transition and accelerating respectively as shown in Figure 4(a-b). Length correction due to perspective distortion and $2 \mathrm{D}$ imaging was required and the same was done by introducing a length correction factor $=$ actual length/ captured length along both longitudinal and vertical directions.

\subsection{Kinematics and dynamics of the particle}

As discussed in particle tracking procedure, the velocity of the sediment particle along and normal to the flow direction were calculated and the resultant particle velocity was obtained accordingly. Similarly, acceleration at several time steps was calculated by applying the forward difference technique using the velocity values. The direction of the particle movement was calculated by analyzing the relative positions of the sediment particle between two-time steps. The mass of the particle was measured in the Environmental Engineering laboratory, IIT Roorkee using a weighing balance that can measure up to $0.1 \mathrm{mg}$. The force values were obtained by multiplying the mass of the sediment particle by the acceleration at different positions. The plots of the parameters are shown in Figure 5(a-d).

\subsection{Critical flow and bed shear stress upstream of ramp}

The movement of $2.18 \mathrm{~mm}$ particle over the smooth bed upstream of the ramp was started at $17.1 \mathrm{l} / \mathrm{s}$ discharge. The corresponding critical velocity of flow was about $0.27 \mathrm{~m} / \mathrm{s}$. Whereas, the movement of same sized particle over the ramp was started at $21.15 \mathrm{l} / \mathrm{s}$ discharge for a critical velocity of $0.315 \mathrm{~m} / \mathrm{s}$. For those two cases the corresponding shear velocity and bed shear stress upstream of the ramp were obtained by analyzing the velocity distribution attained after measuring the velocity profile over the bed. The velocity distribution data were fitted in the Prandtl-Karman logarithmic equation [15-16] for smooth bed condition [14,17]. The calculated critical shear stresses were $0.192 \mathrm{~N} / \mathrm{m}^{2}$ and $0.23 \mathrm{~N} / \mathrm{m}^{2}$ respectively. It was observed that around $20 \%$ additional bed shear stress upstream of the ramp was required to move the sediment over the ramp.

\subsection{Discussions}

The main parameter that governs the sediment motion is the velocity. The flow pattern near and over a ramp was studied experimentally to understand the movement of sediment over the ramp. It was observed in Figure 3 that the upward velocity component of the flow got increased as the flow approached towards the ramp and the same was very high over the ramp. A backward flow was observed over the ramp, near its boundary. 

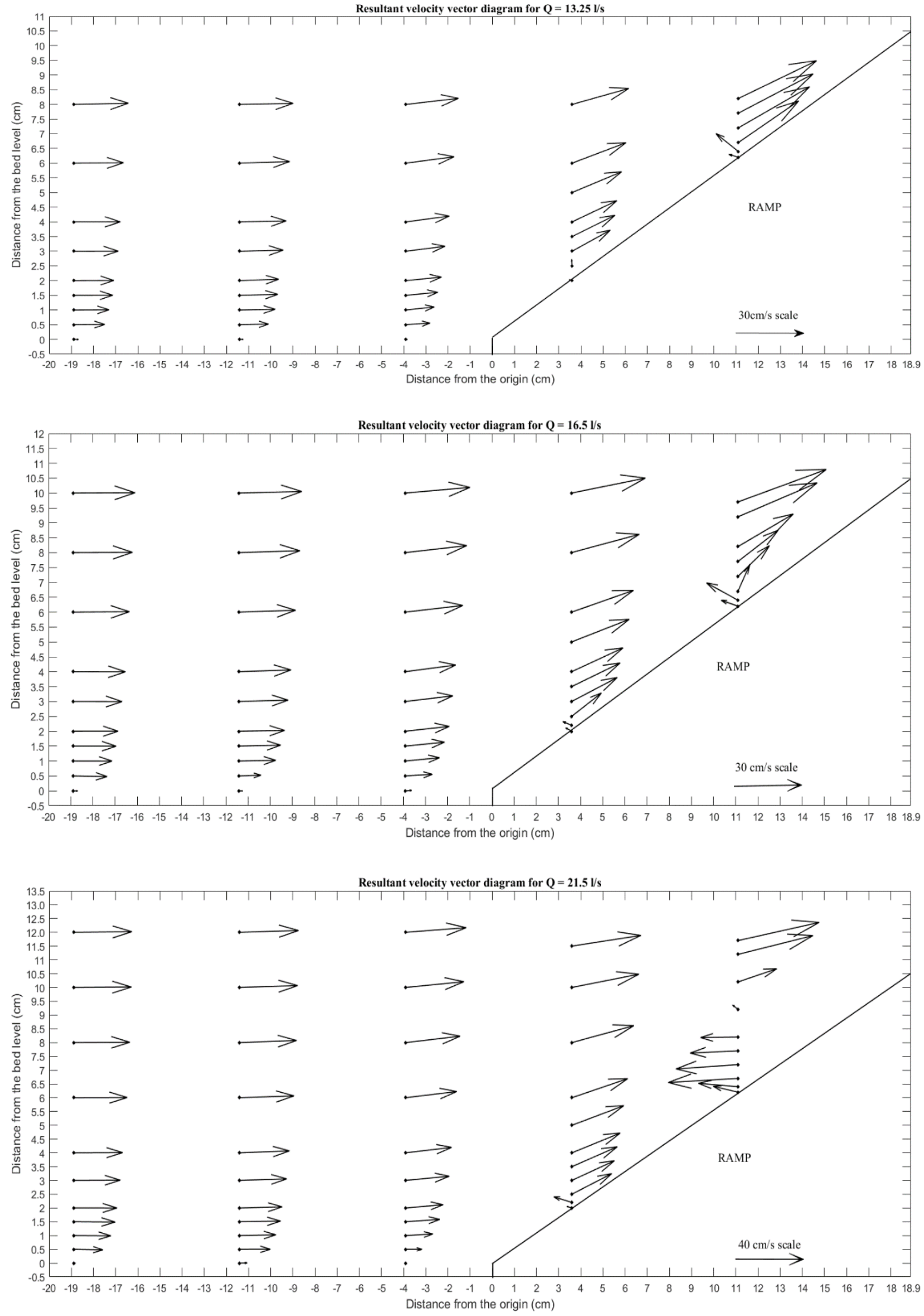

Figure 3. Resultant velocity vector diagrams for different conditions 


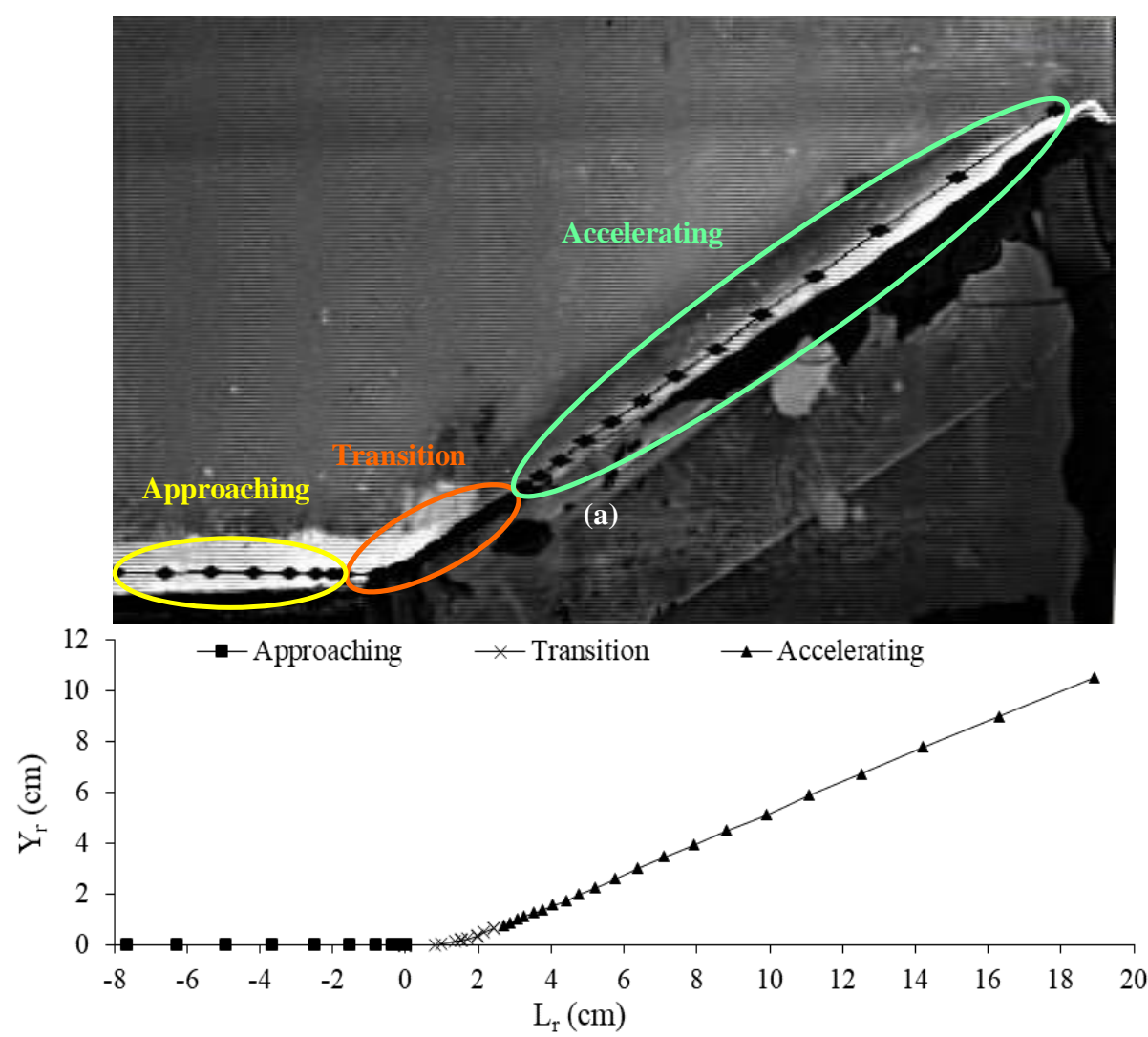

(b)

Figure 4(a-b). Tracked sediment path

It was observed and represented in Figure 5(a) that the approach velocity of the sediment particle reduced due to the presence of the ramp. There was very slow movement of the particle at the beginning of the ramp, in the transition part of the path for about 3.8 seconds. After that time span, the sediment accelerated, and its velocity increased along the ramp towards the flow direction. The observed particle velocity near the end of the ramp was $62.44 \mathrm{~cm} / \mathrm{s}$, where the mean observed flow velocity was around $86.1 \mathrm{~cm} / \mathrm{s}$. The acceleration and the applied force on the moving particle enhanced as the sediment moved further downstream as shown in Figure 5(b-c). The angle of orientation of the path of sediment movement in the accelerating segment as shown in Figure 4(a-b) was found to be within 25.6 to 35.7 degree to the horizontal axis, which was almost parallel to the ramp (ramp is having an inclination of 29.055 degree to the horizontal axis). Figure 5(d) represents the orientation of velocity vector during the particle movement over the ramp.

\section{Conclusions}

The flow pattern near and over a ramp was studied experimentally using ADV to understand the movement of sediment over a ramp. As the flow approached towards the ramp, its upward velocity component got increased and the increment was very significant over the ramp as mentioned in Table 2. A reverse flow was observed over the ramp, near its boundary that may be due to the flow separation in that region. The movement of sediment particles over the ramp having a smooth upstream bed was studied experimentally using high-speed imaging techniques and image processing software. The sediment had very little movement for about 3.8 seconds near the ramp. After that duration the sediment accelerated, and its velocity increased along the ramp and even reached to a value $62.44 \mathrm{~cm} / \mathrm{s}$ near the downstream end of the ramp where the mean observed flow velocity was around 86.1 $\mathrm{cm} / \mathrm{s}$. The acceleration and applied force on the moving particle enhanced as the sediment moved further downstream over the ramp. The path of the sediment movement over the ramp was found to be making angle 25.6 to 35.7 degree to the horizontal axis which was almost parallel to the ramp (29.055 degree). The critical velocity for the movement of sediment particle over the smooth upstream bed and over the ramp were 0.27 and $0.315 \mathrm{~m} / \mathrm{s}$ respectively and additional $20 \%$ bed shear stress upstream of the ramp was required for sediment movement over ramp. 


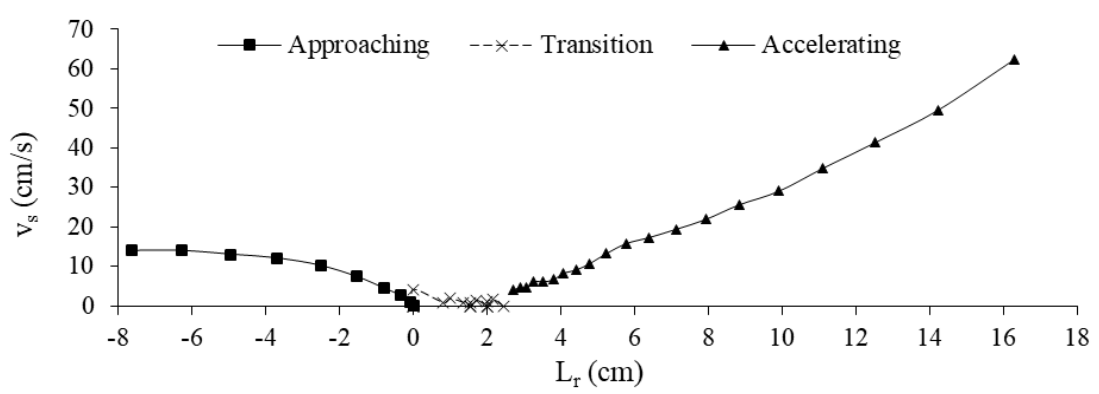

(a) Resultant velocity of sediment during its movement

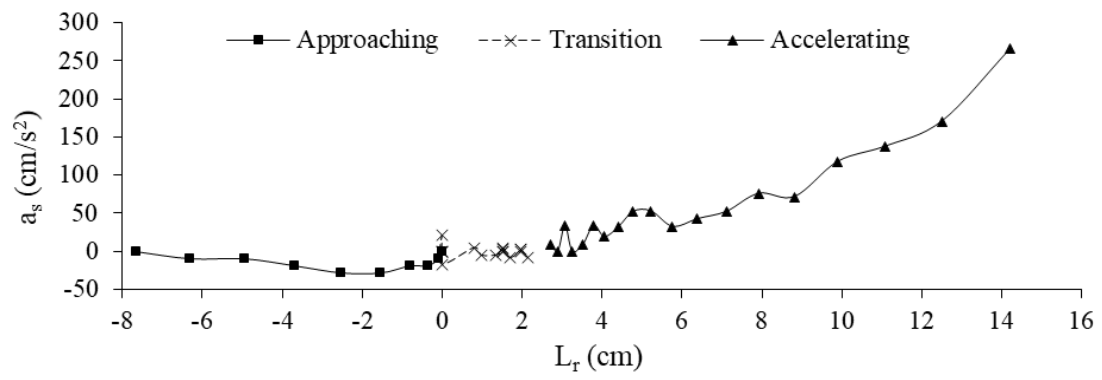

(b) Resultant acceleration of sediment during its movement

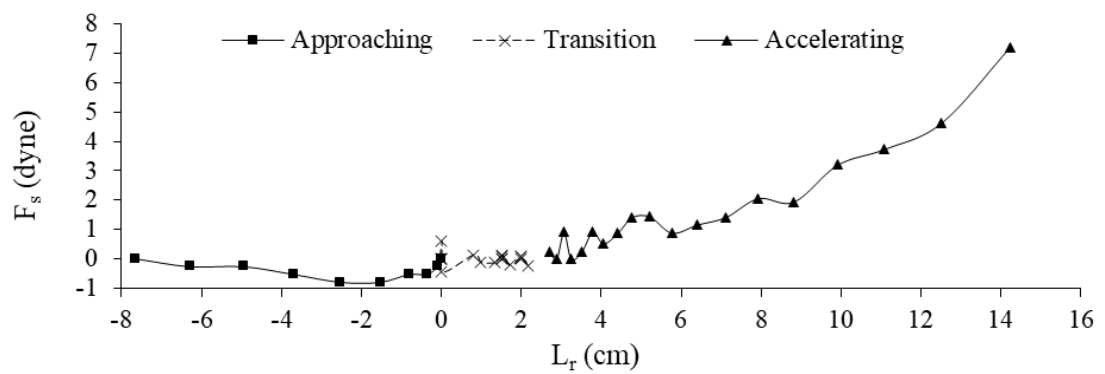

(c) Force on sediment during its movement

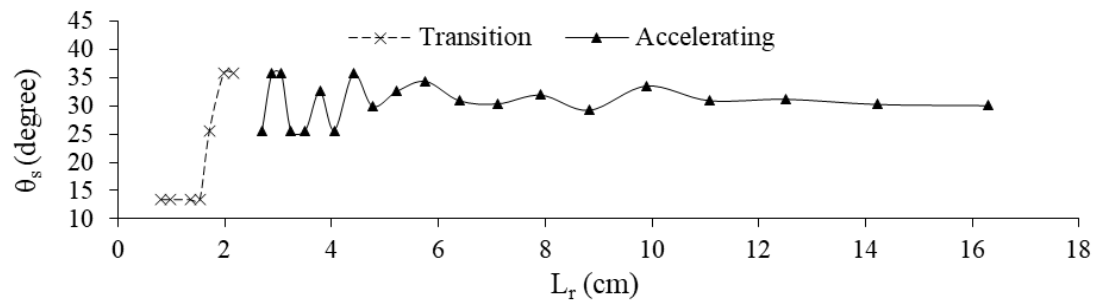

(d) Angle of orientation of particle velocity vector

Figure 5. Kinematics and dynamics parameters of sediment movement for $2.18 \mathrm{~mm}$ particle and $21.15 \mathrm{l} / \mathrm{s}$ discharge

\section{Notations}

a $\quad: \quad$ Resultant acceleration of sediment particle;

$\mathrm{F}_{\mathrm{s}} \quad: \quad$ Resultant force acting on sediment particle;

$\mathrm{L}_{\mathrm{r}} \quad: \quad$ Horizontal distance from the beginning of ramp;

$\mathrm{v}_{\mathrm{s}} \quad: \quad$ Resultant velocity of sediment particle;

$\mathrm{Y}_{\mathrm{r}} \quad: \quad$ Vertical distance from the beginning of ramp;

$\theta_{\mathrm{s}} \quad: \quad$ Angle of orientation of particle velocity vector w.r.t. the longitudinal axis;

\section{References}

[1] Shields A. Application of similarity principles and turbulence research of bed-load movement. [PhD Thesis]. Technical University Berlin. 1936. (in German)

[2] Yalin MS, Karahan E. Incipient of sediment transport, JHD. Proc. ASCE. 1979; 105: HY-11.

[3] Garde RJ, Ranga Raju KG. Mechanics of sediment transportation and alluvial stream problems. Delhi: New Age International;2015. 
[4] Garde RJ, Albertson ML. Sand waves and regimes of flow in Alluvial Channels. In: Proc. IAHR, $8^{\text {th }}$ Congress, Montreal, Vol.4;1959.

[5] Julien YP. Erosion and sedimentation. Cambridge UK: Cambridge University Press;1995.

[6] Meyer-Peter E, Müller R. Formulas for bed load transport. In: Proc. 2nd IAHR congress Stockholm;1948. p.39-64.

[7] Parker G. Surface-based bed-load transport for gravel rivers. J. Hydraulic Res. 1990; 28(4): 417-436.

[8] Fernandez Luque R, Van Beek R. Erosion and transport of bed-load sediment. Journal of hydraulic research. 1976; 14(2): 127-144.

[9] Abbott JE, Francis JR. Saltation and suspension trajectories of solid grains in a water stream. Phil. Trans. R. Soc. Lond. A. 1977; 284 :225-254.

[10] Sumer BM, Oguz B. Particle motions near the bottom in turbulent flow in open channel. J. Fluid Mech. 1978; 86: 109-127.

[11] Drake TG, Shreve RL, Dietrich WE, Whiting PJ, Leopold LB. Bedload transport of fine gravel observed by motion-picture photography. Journal of Fluid Mechanics. 1988; 192: 193-217.

[12] Lee HY, Hsu IS. Investigations of saltating particle motions. J. Hydraulic Eng. 1994; 120(7): 831-845.

[13] Mazumder BS, Bhattacharyya A, Ojha SP. Near-bed particle motion due to turbulent flow using image processing technique. J. Flow Visual. \& Image Process. 2008; 15(1): 1-16.

[14] Ramesh B, Kothyari UC, Murugesan K. Near-bed particle motion over transitionally-rough bed. Journal of Hydraulic Research. 2011; 49(6): 757-765.

[15] Von Karman T. Mechanical similitude and turbulence. Nachrichten Ges. Wiss. Göttingen Math. -Phys. Klasse.1930: 58-76. (in German)

[16] Prandtl L. For turbulent flow in tubes and longitudinal plates. Ergebn. Aerodyn. Versuchsanstalt Göttingen. 1932; 4: 18-29. (in German)

[17] Carvalho E, Maia R, Proença MF. Shear stress measurements over smooth and rough channel beds. River Flow 2010; 2010.p. 367-375.

[18] Kothyari UC, Tiwari AK, Singh R. Estimation of temporal variation of sediment yield from small catchments through the kinematic method. Journal of hydrology. 1997; 203: 39-57.

[19] Jain MK, Kothyari UC, Raju KG. GIS based distributed model for soil erosion and rate of sediment outflow from catchments. Journal of Hydraulic Engineering. 2005; 131(9): 755-769.

[20] Voulgaris G, Trowbridge JH. Evaluation of the acoustic Doppler velocimeter (ADV) for turbulence measurements. Journal of Atmospheric and Oceanic Technology. 1998; 15(1): 272-289.

[21] Sharma N, Tiwari H. Experimental study on vertical velocity and submergence depth near Piano Key Weir. Labyrinth and Piano Key Weirs II-PKW. 2013.p. 93-100.

[22] Garde RJ, Mirajgaoker AG. Engineering fluid mechanics. Roorkee: Nem Chand and Bros;2002.

(C) 2019 by the author(s). This work is licensed under a Creative Commons Attribution 4.0 International License (http://creativecommons.org/licenses/by/4.0/). Authors retain copyright of their work, with first publication rights granted to Tech Reviews Ltd. 